\title{
Mesenterite esclerosante: achado incidental em paciente assintomático.
}

\author{
Rafaela Baesso Reddig1; João Manoel Lumertz Francisco1; Amanda \\ Coelho Zilio'; Smile Calisto da Costa Becker²; Roberto Gabriel
}

Salvaro $^{3}$

\section{Resumo}

INTRODUÇÃO: Mesenterite esclerosante (ME) é uma desordem rara e idiopática caracterizada por inflamação crônica da gordura mesentérica. Espectro de uma mesma doença, pode evoluir de inflamação inespecífica à fibrose e retração do mesentério. Sua prevalência varia de $0,16 \%$ a 7,80\% e estudos referem associação com neoplasia maligna subjacente em 1 a 70\% dos casos. Há discreto predomínio em homens, brancos, entre a $5^{\mathrm{a}}$ e $7^{\mathrm{a}}$ décadas de vida. Mecanismos fisiopatológicos sugeridos incluem cirurgia ou trauma abdominal prévios, doenças autoimunes, síndrome paraneoplásica, lesão isquêmica e infecção. A apresentação clínica depende do estágio de evolução da doença, podendo ser assintomática ou com sinais e/ou sintomas inespecíficos (dor abdominal, náusea e vômito, anorexia, febre, perda de peso, alteração do hábito intestinal, saciedade precoce e presença de massa abdominal). Geralmente tem curso benigno, estável ou de progressão lenta. O diagnóstico é estabelecido por avaliação histológica em paciente com achados radiológicos compatíveis (tipicamente uma

\footnotetext{
${ }^{1}$ Graduando(a) em Medicina, Universidade do Extremo Sul Catarinense.

${ }^{2}$ Médico Gastroenterologista, Especialização - Residência médica em Gastroenterologia pelo Hospital Nossa Senhora da Conceição, professor da Universidade do Extremo Sul Catarinense (smilebecker@gmail.com).

${ }^{3}$ Médico Cardiologista, Mestrado em Ciências da Saúde pela Universidade Federal do Rio Grande do Sul, professor da Universidade do Extremo Sul Catarinense (robertosalvaro@gmail.com).
} 
massa de tecido mole no mesentério do intestino delgado). MÉTODO: Relato de caso. RESULTADOS: Paciente assintomático, 67 anos, masculino, diabético, hipertenso e dislipidêmico submetido à ecografia de abdome para avaliação de esteatose hepática. Evidenciado infiltração adiposa em pâncreas e espessamento heterogêneo dos tecidos moles intraperitoneais na região omental. Estudo complementado por tomografia contrastada de abdome, com achado de densificação da gordura mesentérica ao nível dos vasos mesentéricos superiores e ressonância magnética com as seguintes alterações radiológicas: extensa área de hiperintensidade de sinal em T2 e hipointensidade em T1, envolvendo a porção central e a gordura do mesentério, principalmente adjacente ao mesogastro, com pequenos linfonodos de permeio. Prosseguiu-se a investigação por videolaparascopia. Identificado espessamento do mesentério de todo intestino delgado; realizadas biópsias. Anatomopatológico indicou inflamação crônica inespecífica com histiócitos xantomatosos em tecido adiposo. Endoscopia digestiva alta, colonoscopia e raio $\mathrm{X}$ de tórax sem alterações. Diagnóstico de $\mathrm{ME}$ assintomática sem indicação de tratamento medicamentoso ou cirúrgico. CONCLUSÕES: ME é uma doença frequentemente assintomática, muitas vezes diagnosticada por achado incidental em exames de imagem. A associação desta enfermidade com neoplasia subjacente deve alertar o médico para investigação complementar.

Palavras Chave: mesenterite esclerosante; mesentério 